\title{
Influence of dietary replacement of sunflower oil with milk thistle (Silybum marianum) oil on chicken meat quality and antioxidant status of liver
}

\author{
Gordana Kralik ${ }^{1}$, Zlata Kralik ${ }^{1}$, Eva Straková ${ }^{2}$, Marcela Šperanda ${ }^{3}$, Igor Kralik ${ }^{4}$, \\ Ivica Strelec ${ }^{5}$
}

\author{
${ }^{1}$ Josip Juraj Strossmayer University of Osijek, Faculty of Agriculture, \\ Department of Special Zootechnique, Osijek, Croatia \\ ${ }^{2}$ University of Veterinary and Pharmaceutical Science Brno, Faculty of Veterinary Hygiene end Ecology, \\ Department of Nutrition, Animal Husbandry and Animal Hygiene, Brno, Czech Republic \\ ${ }^{3}$ Josip Juraj Strossmayer University of Osijek, Faculty of Agriculture, Department \\ of Animal Breeding, ${ }^{4}$ Department of Agroeconomics, ${ }^{5}$ Faculty of Food Technology, \\ Department of Applied Chemistry and Ecology, Osijek, Croatia
}

Received March 27, 2015

Accepted September 23, 2015

\begin{abstract}
The research focused on the effects of dietary replacement of 3\% sunflower oil (SO group) with 3\% milk thistle oil (MTO group) on the technological quality of meat, such as $\mathrm{pH}$ value, colour (CIE L*, CIE a*, CIE b*), drip loss (\%), shear force (N), and cooking loss (\%), as well as on the content of fatty acid lipids in broiler breast and thigh muscles. Significant difference $(P<0.05)$ was determined for $\mathrm{pH}_{\mathrm{i}} \mathrm{pH}_{\mathrm{u}}, \mathrm{CIE} \mathrm{a}^{*}, \mathrm{CIE} \mathrm{b}^{*}$ values between groups, although the values for the stated indicators were within the standard range. Lipids of breast meat of the MTO group contained more arachidic acid $(P<0.001)$, octadecenoic acid isomer $\mathrm{B}(P=0.047)$ and eicosatrienoic acid $(P=0.041)$, and less $\alpha$-linolenic acid $(P<0.001)$ and $\Sigma$ n-3PUFA. Lipids of thigh meat of the MTO group contained more $\Sigma$ SFA, myristoleic acid, eicosatrienoic acid $(P<0.05)$ and eicosenoic acid $(P<0.001)$, and less $\alpha$-linolenic acid, and had narrower $\Sigma \mathrm{n}-3 / \mathrm{n}-6$ PUFA ratio than the SO group. According to the antioxidant status of broiler liver, there was significantly higher catalase activity determined in the MTO group.
\end{abstract}

Breast meat, technological quality, fatty acids, catalase, glutathione-S-transferase

Broiler meat and its products are consumed worldwide. The quality of meat highly depends on the content and composition of fat in meat. Oils in diets are required as a source of energy. This research focused on the usage of milk thistle (Silybum marianum) oil as a replacement for sunflower oil. Milk thistle is a plant used for production of silymarin - an ingredient which acts as antioxidant, absorbs free radicals and shows anti-inflammatory activity (Fiebrich and Koch 1979; Bosisio et. al. 1992; De La Puerta et al. 1996). Positive effects of this medicinal plant referring to improved health conditions and better performances of broilers were reported by Yakhkeshi et al. (2012) and Elmakki et al. (2013). Many plants, including also Silybum marianum, have been examined for their influences in treatments of some liver disorders (Luper 1998). Several studies demonstrated its anti-inflammatory effects (Polyak et al. 2007), including mast cell stabilization, inhibition of neutrophil migration, Kuppfer cell inhibition, strong inhibition of leukotriene synthesis, and prostaglandin formation (Kang et al. 2004). Scott (1998) pointed out the significant activity of milk thistle in medical applications, since it was one of the oldest known plants containing active components, such as silybin (50-60\%), isosilybin (5\%), silydianin (10\%), silychristin (20\%), all referred to under the common name of silymarin. Silymarin acts as a hepatoprotective agent, and is used in treatments of liver regeneration, fatty liver disease, cirrhosis, and toxic radiation. Immunomodulating

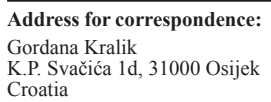

Phone: +385(0) 31554863
Fax: +385(0)315548 53
E-mail: gkralik@pfos.hr
http://actavet.vfu.cz/ 
effects are also attributed to silymarin. Cold pressed oil of milk thistle is an excellent source of linoleic acid (C18: 2, n-6), which is important in synthesis of biologically active substances, such as prostaglandin, prostacyclin, tromboselicines and other substances that regulate metabolism. For its high content of linoleic acid, milk thistle oil is similar to sunflower oil. Several authors (Mekala et al. 2006; Schiavone et al. 2007; Mojahedtalab et al. 2013) investigated supplementation of silymarin in broiler diets and its effects on growth, consumption, and conversion of feed. However, there is still lack of knowledge on influences of milk thistle oil on the technological properties of broiler meat, fatty acid profile in muscles, as well as liver enzymes that regulate metabolic processes, all of which were the objectives of our research. Kralik et al. (2015) reported on the influences of milk thistle oil on the fattening characteristics of broilers and on carcass quality. This paper presents a continuation of that research.

\section{Materials and Methods}

The research was carried out on a total of 60 Cobb 500 broilers, of which 30 broilers $(3 \times 10)$ were included in the SO group fed $3 \%$ sunflower oil (SO), and 30 broilers $(3 \times 10)$ were included in the MTO group fed $3 \%$ milk thistle oil (MTO). During the first three weeks of fattening, broilers consumed powdered starter diets of the same composition. At the beginning of the $4^{\text {th }}$ fattening week (since the $22^{\text {nd }}$ day), broilers were randomly divided into two groups and fed pelleted finisher diets of modified composition. The feeding and watering of broilers was $a d$ libitum and automatically regulated.

The starter diet contained $24.3 \%$ crude protein and $13.5 \mathrm{MJ} \mathrm{kg}^{-1} \mathrm{ME}$, and the finisher diets were balanced at

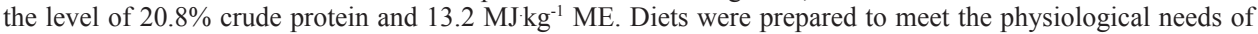
the Cobb 500 broilers. Broilers were fattened in groups and kept on deep litter. The ambient temperature was gradually reduced from 32 to $20{ }^{\circ} \mathrm{C}$ during the experiment. Relative humidity inside the room varied from $65 \%$ to $75 \%$. The lighting programme was $24 \mathrm{~h} /$ per day during the first eight days of the experiment, and afterwards it included $3 \mathrm{~h}$ darkness. After 42 days, the broilers were weighed, slaughtered and defeathered. Carcasses were processed according to the EC regulations 543/2008 and cut into main parts: breasts, drumsticks with thighs, backs and wings. Breast and thigh muscles were used in the research.

Meat quality indicators referred to $\mathrm{pH}_{\mathrm{i}}\left(45 \mathrm{~min}\right.$ after the slaughtering of broilers) and $\mathrm{pH}_{\mathrm{u}}(24 \mathrm{~h}$ after the slaughtering of broilers), determined on the left side of $\mathrm{m}$. pectoralis major by a probe of the digital $\mathrm{pH}$ meter Mettler MP 120-B. Meat colour was determined $24 \mathrm{~h}$ after the cooling of carcasses by a chromatograph Minolta Camera CR-300 and presented as CIE L*, a* and b* (Commission Internationale de l'Eclairage 1976), referring to lightness (black-white axis), degree of redness (red-green spectrum), and degree of yellow (yellow-blue spectrum). Calibration of the device was performed by using the standard white plate $(\mathrm{Y}=93.0, \mathrm{x}=0.3195 ; \mathrm{y}=0.3324)$. The optical lens diameter was $8 \mathrm{~mm}$, illumination D65, and standard observation $10^{\circ}$. Prior to the measuring of colour, there was a fresh section made on the breast muscle and then left for 10 min to develop colour. The colour of each breast muscle resulted from three consecutive measurements, and was presented as a mean value. Resistance of muscles to cutting was determined by TA.XTplus Texture Analyser device with Warner-Bratzler blade according to the modified method of Liu et al. (2004). After storing the samples at $-20^{\circ} \mathrm{C}$ for 14 days, the meat was defrosted, closed in plastic bags, cooked in a water bath at $85{ }^{\circ} \mathrm{C}$ for $25 \mathrm{~min}$, and then cooled to room temperature. There were three subsamples $(3 \mathrm{~cm} \times 1.9 \mathrm{~cm} \times 1.9 \mathrm{~cm})$ taken from each sample. Maximum force $(\mathrm{N})$ required for the cutting of a subsample with Warner-Bratzler shear force blade was calculated by Texture Exponent 4.0 software (Stable Microsystems, UK). Drip loss from the breast muscle was determined according to the method of Honikel (1998), as follows: a sample of breast muscle was cut in the diameter of $2 \mathrm{~cm}$ and the height of $3 \mathrm{~cm}$, then it was weighed and kept in a plastic bag in the refrigerator for $48 \mathrm{~h}$ at $+4{ }^{\circ} \mathrm{C}$.

Drip loss was calculated as: drip loss $(\%)=\{$ initial tissue mass $(\mathrm{g})$ - final tissue mass (g) / initial tissue mass $(\mathrm{g})\} \times 100$

Cooking loss was determined in samples of breast muscle tissue, calculated as follows: cooking loss $(\%)=$ $\{$ (sample mass before cooking $(\mathrm{g})$ - sample mass after cooking $(\mathrm{g}) /$ sample mass before cooking $(\mathrm{g})\} \times 100$.

The content of fatty acids in diets and meat were determined by the Chrompack CP-9000 chromatograph equipped with flame ionization detector. Quantitative evaluation was obtained on the basis of percentage relations of chromatographic peaks of pure methyl ester and heights of chromatographic peaks of samples. Percent proportion of fatty acids in a sample was calculated as a function of comparative weight percentage of fatty acid methyl ester (Csapo et al. 1986). Individual fatty acids were presented as \% of total fatty acids.

In order to perform homogenization and extraction of the tissue, broiler liver was cut to thin slices, slices diced, and $150 \mathrm{mg}$ of diced liver was mixed with 1.5 of $50 \mathrm{mM}$ phosphate buffer $\mathrm{pH} 7.0$ containing $5 \mathrm{mM}$ EDTA-2Na. After vortexing for $15 \mathrm{~s}$, ultrasonic homogenization of suspension was performed in ice-cold water bath $\left(+4{ }^{\circ} \mathrm{C}\right)$, 
during four 30-s intervals at full cycle and 100\% amplitude. Extracts were clarified by centrifugation (15 $000 \mathrm{~g}$, $4{ }^{\circ} \mathrm{C}, 10 \mathrm{~min}$ ) and used for protein content and antioxidant enzyme activity determination. The protein content in extracts was determined by Bradford method (Bradford 1976) with bovine serum albumin as a standard.

Free sulfhydryl group determination was performed according to the method of Sedlak and Lindsay (1968). Prior to free sulfhydryl content determination, proteins from extracts were removed by 15 min precipitation with $10 \%$ trichloroacetic acid, followed by supernatant clarification $\left(15000 \mathrm{~g}, 4{ }^{\circ} \mathrm{C}, 10 \mathrm{~min}\right)$. Glutathione reductase (GR), glutathione-S-transferase (GST) and catalase (CAT) were measured in liver extracts diluted as follows: (i) 10-fold dilution was used for GR and GST activity determination, and 100-fold CAT. Catalase activity was determined by the method of A ebi (1986) using hydrogen peroxide as a substrate. One unit (U) of catalase activity was defined as the amount of enzyme decomposing $1 \mu \mathrm{mol}$ of hydrogen peroxide to oxygen and water per minute at $\mathrm{pH} 7.0,25^{\circ} \mathrm{C}$ and $10 \mathrm{mM}$ hydrogen peroxide concentration. Glutathione reductase activity was determined by UV assay using glutathione reductase assay kit (Sigma, USA). One unit (U) of glutathione reductase activity was defined as amount of enzyme causing oxidation of $1 \mu \mathrm{mol}$ of NADPH at $25^{\circ} \mathrm{C}$ and $\mathrm{pH}$ 7.5. Glutathione-Stransferase activity was measured by modified method of Habig et al. (1974) as described by Habdous et al. (2002). The reaction mixture $(1.1 \mathrm{ml})$ contained $1 \mathrm{mM}$ EDTA, $2 \mathrm{mM}$ 1-chloro-2,4-dinitrobenzene (CDNB) as a substrate and $5 \mathrm{mM}$ reduced glutathione (GSH) as co-substrate in $100 \mathrm{mM}$ potassium phosphate buffer at pH 5.5. One unit (U) of GST activity was defined as the amount of enzyme producing $1 \mu \mathrm{mol}$ of GS-DNB conjugate at $\mathrm{pH} 5.5$ and $25^{\circ} \mathrm{C}$.

Analysis of variance (ANOVA) was performed by using the GLM procedure for two treatments (SO and MTO). Obtained differences between groups were tested by the Fisher's LSD test. Significant differences between experimental groups were assigned with different subscripts ( $\left.{ }^{\mathrm{a}, \mathrm{b}}-P<0.05,{ }^{\mathrm{A}, \mathrm{B}}-P<0.01,{ }^{\mathrm{X}, \mathrm{Y}}-P<0.001\right)$.

\section{Results}

Table 1 presents concentrations of fatty acids in plant oils and in broiler diets. The experiment proved that milk thistle oil was richer in n-6 PUFA (63.11 vs $58.85 \%)$ and poorer in n-3 PUFA $(0.30 \%$ vs $0.41 \%)$ compared to sunflower oil. The finisher diet for the MTO broiler group contained more $\Sigma$ SFA (16.92\% vs $13.73 \%)$, and less $\Sigma$ MUFA $(23.89 \%$ vs $25.89 \%$ ) compared to the finisher diet given to the SO broiler group. Palmitic acid (C16:0) was the most represented in $\Sigma$ SFA of both oils (13.46\% vs $12.79 \%$ ). In $\Sigma$ MUFA, oleic acid (C18:1n9c) was represented at a higher concentration in the finisher diet of SO compared to MTO group $(23.70 \%$ vs $21.25 \%)$. No differences were determined in the content of n-6 PUFA between SO and MTO finisher diets. The finisher diet of the SO group contained more $\Sigma$ n-3 PUFA (referring to $\alpha$-linolenic acid, C18:3n3) than the finisher diet of MTO group (2.33\% vs $1.13 \%)$. The ratio of $n-6 / n-3$ PUFA was more favourable in the SO finisher diet compared to the MTO finisher diet (24.91:1, i.e. 51.38).

Research into the technological and sensory quality of breast muscles indicated higher $\mathrm{pH}_{\mathrm{i}}$ values $(P=0.026)$, and lower $\mathrm{pH}_{\mathrm{u}}$ values $(P=0.003)$ in the $\mathrm{SO}$ group compared to the MTO group (Table 2). The values of $\mathrm{pH}_{\mathrm{i}}$ and $\mathrm{pH}_{\mathrm{u}}$ obtained in our research were within the standard range defined for meat of normal technological traits. Results of breast muscle tissue colour showed a higher CIE a* value $(P<0.030)$, and lower CIE $\mathrm{b}^{*}$ value $(P<0.001)$ in the SO group compared to the MTO group.

Breast muscles of the SO group had greater values of drip loss $(\%)$, shear force $(\mathrm{N})$ and cooking loss (\%) than the MTO group, however, the differences were not significant $(P>0.05)$.

White meat of the MTO group contained more octadecenoic acid isomer $(2.47 \% \mathrm{vs}$ $2.08 \% ; P=0.047)$, eicosenoic acid $(0.42 \%$ vs $0.30 \% ; P<0.001)$, as well as eicosatrienoic acid $(0.96 \%$ vs $0.74 \% ; P=0.041)$ compared to white meat of the SO group (Table 3$)$. Breast muscle lipids of the SO group exhibited significantly higher concentration of $\alpha$-linolenic acid $(1.03 \%$ vs $0.50 \% ; P<0.001)$, slightly higher concentration of eicosatrienoic acid $(0.06 \%$ vs $0.04 \%, P=0.021)$, and significantly lower concentration of eicosapentaenoic acid $(0.22 \%$ vs $0.32 \%, P=0.040)$ compared to breast muscle lipids of the MTO group. The sum of n-3 PUFA in breast muscle lipids in the SO group was higher compared to the MTO group (2.48\% vs $1.91 \%, P>0.05)$. Both broiler groups had a high and unfavourable n-6/n-3 PUFA ratio (15.48 and 17.76) in breast meat. 
Table 1. Concentrations of fatty acids in plant oils and chickens' diet.

\begin{tabular}{|c|c|c|c|c|c|}
\hline \multirow{2}{*}{ Fatty acid } & \multirow{2}{*}{ Sunflower oil } & \multirow{2}{*}{ Milk thistle oil } & \multirow{2}{*}{ Starter diet } & \multicolumn{2}{|c|}{ Finisher diets } \\
\hline & & & & SO group & MTO group \\
\hline Lauric acid (C 12:0) & 0.20 & - & 0.03 & 0.01 & 0.02 \\
\hline Myristic acid (C 14:0) & 0.20 & 0.09 & 0.19 & 0.10 & 0.21 \\
\hline Pentadecanoic acid (C 15:0) & 6.30 & 0.02 & 0.06 & 0.03 & 0.06 \\
\hline Palmitic acid (C 16:0) & 8.30 & 8.01 & 17.46 & 12.71 & 13.96 \\
\hline Heptadecanoic acid (C 17:0) & - & 0.07 & 0.35 & 0.12 & 0.10 \\
\hline Stearic acid (C 18:0) & 3.10 & 0.06 & 0.10 & 0.07 & 0.09 \\
\hline Arachidic acid (C 20:0) & 0.15 & 2.32 & 0.51 & 0.28 & 1.38 \\
\hline Behenic acid (C 22:0) & 0.25 & 1.86 & 0.24 & 0.41 & 1.10 \\
\hline$\sum \mathrm{SFA}$ & 18.50 & 12.43 & 18.94 & 13.73 & 16.92 \\
\hline Myristoleic acid (C 14:1) & - & - & - & - & 0.01 \\
\hline Palmitoleic acid isomer (C 16:1) & - & 0.02 & 0.09 & 0.08 & 0.04 \\
\hline Palmitoleic acid (C 16:1n7) & - & 0.07 & 0.35 & 0.12 & 0.10 \\
\hline Elaidic acid (C 18:1n9t) & - & - & 0.27 & 0.12 & 0.11 \\
\hline Oleic acid (C 18:1n9c) & 21.94 & 22.27 & 21.10 & 23.70 & 21.25 \\
\hline Octadecenoic acid isomer A (C 18:1) & 0.10 & 0.46 & 1.05 & 0.75 & 0.56 \\
\hline Octadecenoic acid isomer B (C 18:1) & - & 0.55 & 1.65 & 0.94 & 1.32 \\
\hline Eicosenoic acid (C 20:1n9) & 0.20 & 0.79 & 0.23 & 0.18 & 0.50 \\
\hline$\sum$ MUFA & 22.24 & 24.16 & 24.74 & 25.89 & 23.89 \\
\hline Linoleic (C 18:2n6) & 58.85 & 63.05 & 47.37 & 55.48 & 54.78 \\
\hline Eicosadienoic acid (C 20:2n6) & - & 0.03 & 0.08 & 0.03 & 0.04 \\
\hline Eicosatrienoic acid (C 20:3n6) & - & - & 0.16 & 0.09 & 0.14 \\
\hline Arachidonic acid (C 18:4n6) & - & - & 0.38 & 0.03 & 0.01 \\
\hline Octadecadienoic acid isomer A (C 18:2) & - & - & 1.78 & 0.82 & 1.05 \\
\hline Octadecadienoic acid isomer B (C 18:2) & - & - & 1.21 & 0.59 & 0.73 \\
\hline Octadecadienoic acid isomer C (C 18:2) & - & 0.03 & 1.16 & 0.52 & 0.68 \\
\hline Octadecadienoic acid isomer D (C 18:2) & - & - & 1.09 & 0.49 & 0.63 \\
\hline$\sum \mathrm{n}-6$ PUFA & 58.85 & 63.11 & 53.23 & 58.05 & 58.06 \\
\hline$\alpha$-linolenic acid (C 18:3n3) & 0.41 & 0.24 & 3.09 & 2.33 & 1.13 \\
\hline Eicosatrienoic (C 20:3n3) & - & 0.06 & - & - & \\
\hline$\overline{\sum n-3}$ PUFA & 0.41 & 0.30 & 3.09 & 2.33 & 1.13 \\
\hline n-6/n-3 PUFA & 143.54 & 210.37 & 17.23 & 24.91 & 51.38 \\
\hline
\end{tabular}

SO 3\% sunflower oil; MTO 3\% milk thistle oil

The fatty acid profile in thigh muscle lipids is presented in Table 4. The MTO group was richer in myristic acid $(0.43 \%$ vs $0.36 \%, P=0.032)$, palmitic acid $(21.58 \%$ vs $19.90 \% ; P$ $=0.014)$ arachidic acid $(0.20 \%$ vs $0.11 \% ; P<0.001)$, myristoleic acid $(0.08 \%$ vs $0.05 \%$; $P=0.044)$, palmitoleic acid isomer $(0.43 \%$ vs $0.34 \% ; P=0.028)$ and eicosenoic acid $(0.36 \%$ vs $0.27 \% ; P<0.001)$. Lipids in thighs of the SO group contained more linoleic acid (34.80\% vs $29.10 \% ; P=0.024)$, and less eicosatrienoic acid $(0.40 \%$ vs $0.48 \% ; P=0.022)$ than those of the MTO group. Lipids in thighs of the SO group had more $\alpha$-linolenic acid $(1.57 \%$ vs $0.87 \% ; P<0.001)$, and more eicosatrienoic acid $(0.03 \%$ vs $0.01 \% ; P=0.003)$ compared to the MTO group. Higher concentration of $\Sigma$ n-3 PUFA was determined in lipids 
Table 2. Breast muscle quality traits.

\begin{tabular}{|c|c|c|c|}
\hline Indicator & $\mathrm{SO}$ group $(\bar{x} \pm \mathrm{SD})$ & MTO group $(\bar{x} \pm \mathrm{SD})$ & $P$ value \\
\hline$\overline{\mathrm{pH}_{\mathrm{i}}(\mathrm{n}=30)}$ & $6.10^{\mathrm{a}} \pm 0.19$ & $6.09^{b} \pm 0.14$ & 0.026 \\
\hline $\mathrm{pH}_{\mathrm{u}}(\mathrm{n}=30)$ & $5.75^{\mathrm{B}} \pm 0.17$ & $5.88^{\mathrm{A}} \pm 0.15$ & 0.003 \\
\hline CIE L* $(n=30)$ & $49.40 \pm 3.91$ & $49.51 \pm 2.42$ & 0.893 \\
\hline CIE a* $(n=30)$ & $2.03^{\mathrm{a}} \pm 0.62$ & $1.66^{\mathrm{b}} \pm 0.29$ & 0.030 \\
\hline $\mathrm{CIE} \mathrm{b}^{*}(\mathrm{n}=30)$ & $9.81^{\mathrm{Y}} \pm 2.16$ & $12.01^{\mathrm{X}} \pm 1.70$ & $<0.001$ \\
\hline Drip loss, $\%(n=10)$ & $2.18 \pm 0.90$ & $1.71 \pm 0.34$ & 0.069 \\
\hline Shear force WBSF, N $(n=10)$ & $36.34 \pm 7.75$ & $35.83 \pm 3.31$ & 0.865 \\
\hline Cooking loss, $\%(n=10)$ & $19.72 \pm 2.13$ & $19.42 \pm 3.23$ & 0.816 \\
\hline
\end{tabular}

SO 3\% sunflower oil, MTO 3\% milk thistle oil; $\bar{x}=$ arithmetic means; SD = standard deviation; ${ }^{\mathrm{a}, \mathrm{b}} P<0.05$; ${ }^{\mathrm{A}, \mathrm{B}} \mathrm{P}<0.01 ;{ }^{\mathrm{X}, \mathrm{Y}} \mathrm{P}<0.001$

of thighs of the SO group $(2.29 \%$ vs $1.57 \% ; P<0.001)$, as well as a narrower $n-6 / n-3$ PUFA ratio (17.43:22.36; $P<0.001)$ if compared to MTO group.

Silybum marianum oil dietary supplementation did not exhibit a significant effect on the free sulfhydryl group content in broiler liver. However, increased $(P=0.020)$ catalase activity was determined in liver extracts of broilers fed Silybum marianum oil (Table 5). A decrease of glutathione-S-transferase $(P=0.005)$ and glutathione reductase $(P<0.001)$ activity was determined in this research.

\section{Discussion}

In this research, it was important to compare concentrations of $\alpha$-linolenic acid in the feed and in meat because $\alpha$-linolenic acid is a precursor of EPA and DHA. During the processes of desaturation and elongation with specific enzymes, $\alpha$-linolenic acid is converted to $n-3$ PUFA of a long carbon chain. Finisher diets used in this research contained $2.33 \% \alpha$-linolenic acid in lipids of the SO group, and $1.13 \%$ in lipids of the MTO group. Analysis of breast muscle samples proved significantly higher concentration of EPA $(P=0.40)$ in the MTO group compared to the SO group. These results were in accordance with the findings of Youdim et al. (2000) and Cortinas et al. (2004). Relations between the content of PUFA in the feed and in broiler muscle tissue were explained by Cortinas et al. (2004) as a combination of FA deposition from the feed and endogenous synthesis, which was also confirmed by Kralik et al. (2012). Endogenous synthesis of EPA was not determined in lipids of thigh muscles. This research proved two aspects of the technological quality of meat. It was determined that $3 \%$ sunflower oil can be replaced with $3 \%$ milk thistle oil from the $22^{\text {nd }}$ to $42^{\text {nd }}$ day of broiler fattening. The fatty acid profile and the ratio of n-6/n-3 PUFA were more favourable in muscle lipids of broilers fed sunflower oil. Since both types of oil contain high concentrations of $n-6$ PUFA, it is advisable to combine them with oils that are rich in n-3 PUFA to reach a balance of n-6/n-3 PUFA in diets, and consequently, in the lipids of broiler meat.

The value of $\mathrm{pH}_{\mathrm{i}}$ in breast muscles was higher in the $\mathrm{SO}$ group than in the MTO group. Slower glycolytic processes increased $\mathrm{pH}_{\mathrm{u}}$ value in the MTO group compared to the SO group (Table 2). Le Bihan-Duval et al. (2008) pointed out that the rate of decrease of $\mathrm{pH}$ value post mortem, as well as the final $\mathrm{pH}$ value were important for the technological quality of meat. A rapid decline in $\mathrm{pH}$ results in pale, soft, and exudative breast muscles (PSE), and a high $\mathrm{pH}_{u}$ value indicates DFD meat (Dry-Firm-Dark). The authors determined that the $\mathrm{pH}$ value $15 \mathrm{~min}$ p.m. ranged 6.02-6.79, with a mean of 6.45 . The $\mathrm{pH}_{\mathrm{u}}$ value ranged 5.35-6.04, with a mean of 5.64. Raach-Moujahed and Haddad (2013) determined that 
Table 3. Content of fatty acids in lipids of broiler breast muscle ( $\%$ of total fatty acids, $n=5)$.

\begin{tabular}{|c|c|c|c|}
\hline Fatty acid & SO group $\bar{x} \pm \mathrm{SD}$ & MTO group $\bar{x} \pm \mathrm{SD}$ & $P$ value \\
\hline Lauric acid (C12:0) & $0.03 \pm 0.01$ & $0.02 \pm 0.0005$ & 0.180 \\
\hline Myristic acid (C14:0) & $0.38 \pm 0.04$ & $0.37 \pm 0.01$ & 0.794 \\
\hline Pentadecanoic acid (C 15:0) & $0.08^{\mathrm{a}} \pm 0.01$ & $0.06^{\mathrm{b}} \pm 0.01$ & 0.031 \\
\hline Palmitic acid C (16:0) & $23.01 \pm 1.95$ & $24.26 \pm 1.75$ & 0.315 \\
\hline Heptadecanoic acid (C 17:0) & $2.08 \pm 0.61$ & $2.34 \pm 0.69$ & 0.543 \\
\hline Stearic acid (C 18:0) & $0.15 \pm 0.01$ & $0.12 \pm 0.03$ & 0.073 \\
\hline Arachidic acid (C 20:0) & $0.14^{\mathrm{Y}} \pm 0.01$ & $0.26^{\mathrm{X}} \pm 0.04$ & $<0.001$ \\
\hline Behenic acid (C 22:0) & $0.13 \pm 0.03$ & $0.17 \pm 0.03$ & 0.096 \\
\hline$\sum \mathrm{SFA}$ & $25.99 \pm 2.22$ & $27.61 \pm 1.58$ & 0.222 \\
\hline Myristoleic acid (C 14:1) & $0.05 \pm 0.02$ & $0.05 \pm 0.02$ & 0.978 \\
\hline Palmitoleic acid isomer (C 16:1) & $0.29 \pm 0.02$ & $0.34 \pm 0.06$ & 0.163 \\
\hline Palmitoleic acid (C 16:1n7) & $2.07 \pm 0.61$ & $2.34 \pm 0.69$ & 0.543 \\
\hline Octadecenoic acid isomer A (C 18:1) & $1.54 \pm 0.34$ & $2.02 \pm 0.93$ & 0.302 \\
\hline Octadecenoic acid isomer B (C18:1) & $2.08^{b} \pm 0.23$ & $2.47^{\mathrm{a}} \pm 0.30$ & 0.047 \\
\hline Elaidic acid (C18:1n9t) & $0.34 \pm 0.04$ & $0.46 \pm 0.14$ & 0.104 \\
\hline Oleic acid (C18:1n9c) & $27.08 \pm 2.72$ & $28.96 \pm 2.49$ & 0.286 \\
\hline Eicosenoic acid (C20:1n9) & $0.30^{\mathrm{Y}} \pm 0.02$ & $0.42^{\mathrm{x}} \pm 0.03$ & $<0.001$ \\
\hline$\sum$ MUFA & $33.75 \pm 3.16$ & $37.05 \pm 2.83$ & 0.119 \\
\hline Octadecadienoic acid isomer A (C 18:2) & $0.51 \pm 0.10$ & $0.52 \pm 0.20$ & 0.933 \\
\hline Octadecadienoic acid isomer B (C 18:2) & $0.35 \pm 0.07$ & $0.33 \pm 0.13$ & 0.864 \\
\hline Octadecadienoic acid isomer C (C 18:2) & $0.30 \pm 0.06$ & $0.29 \pm 0.12$ & 0.874 \\
\hline Octadecadienoic acid isomer D (C 18:2) & $1.53 \pm 0.50$ & $1.91 \pm 0.57$ & 0.291 \\
\hline Linoleic (C 18:2n6) & $27.90 \pm 2.39$ & $22.01 \pm 2.52$ & 0.005 \\
\hline$\gamma$-linolenic (C 18:3n6) & $0.17 \pm 0.04$ & $0.16 \pm 0.04$ & 0.500 \\
\hline Eicosadienoic (C 20:2n6) & $0.83 \pm 0.19$ & $0.77 \pm 0.16$ & 0.604 \\
\hline Eicosatrienoic acid (C:20:3n6) & $0.74^{\mathrm{b}} \pm 0.09$ & $0.96^{\mathrm{a}} \pm 0.18$ & 0.041 \\
\hline Arachidonic acid (C 20:4n6) & $5.06 \pm 1.70$ & $5.91 \pm 1.27$ & 0.400 \\
\hline Docosatetraenoic acid (C2 2:4n6) & $0.39 \pm 0.16$ & $0.58 \pm 0.23$ & 0.180 \\
\hline$\sum \mathrm{n}-6$ PUFA & $37.78 \pm 3.72$ & $33.43 \pm 3.28$ & 0.085 \\
\hline$\alpha$-linolenic acid (C 18:3n3) & $1.03^{x} \pm 0.14$ & $0.50^{Y} \pm 0.08$ & $<0.001$ \\
\hline Eicosatrienoic (C 20:3n3) & $0.06^{\mathrm{a}} \pm 0.01$ & $0.04^{\mathrm{b}} \pm 0.01$ & 0.021 \\
\hline Eicosapentaenoic acid (C 20:5n3) & $0.22^{\mathrm{b}} \pm 0.04$ & $0.32^{\mathrm{a}} \pm 0.08$ & 0.040 \\
\hline Docosapentaenoic acid (C22:5n3) & $0.69 \pm 0.26$ & $0.54 \pm 0.13$ & 0.300 \\
\hline Docosahexaenoic acid (C22:6n3) & $0.48 \pm 0.22$ & $0.51 \pm 0.18$ & 0.817 \\
\hline$\sum n-3$ PUFA & $2.48 \pm 0.46$ & $1.91 \pm 0.32$ & 0.051 \\
\hline n-6/n-3 PUFA & $15.48 \pm 1.63$ & $17.76 \pm 2.14$ & 0.094 \\
\hline
\end{tabular}

SO 3\% sunflower oil, MTO 3\% milk thistle oil; $\bar{x}=$ arithmetic means; $\mathrm{SD}=$ standard deviation; ${ }^{\mathrm{a}, \mathrm{b}} P<0.05$; ${ }^{\mathrm{X}, \mathrm{Y}} \mathrm{P}<0.001$ 
Table 4. Content of fatty acids in lipids of broiler thigh muscle ( $\%$ of total fatty acids, $n=5)$.

\begin{tabular}{|c|c|c|c|}
\hline Fatty acid & $\mathrm{SO}$ group $\bar{x} \pm \mathrm{SD}$ & MTO group $\bar{x} \pm \mathrm{SD}$ & $P$ value \\
\hline Lauric acid (C12:0) & $0.02 \pm 0.01$ & $0.03 \pm 0.01$ & 0.103 \\
\hline Myristic acid (C14:0) & $0.36^{\mathrm{b}} \pm 0.02$ & $0.43^{\mathrm{a}} \pm 0.05$ & 0.032 \\
\hline Pentadecanoic acid (C 15:0) & $0.08 \pm 0.01$ & $0.07 \pm 0.01$ & 0.109 \\
\hline Palmitic acid C (16:0) & $19.90^{\mathrm{b}} \pm 0.92$ & $21.58^{\mathrm{a}} \pm 0.76$ & 0.014 \\
\hline Heptadecanoic acid (C 17:0) & $2.60 \pm 2.62$ & $3.56 \pm 0.84$ & 0.073 \\
\hline Stearic acid (C 18:0) & $0.14 \pm 0.05$ & $0.11 \pm 0.02$ & 0.349 \\
\hline Arachidic acid (C 20:0) & $0.11^{\mathrm{Y}} \pm 0.01$ & $0.20^{\mathrm{x}} \pm 0.02$ & $<0.001$ \\
\hline Behenic acid (C 22:0) & $0.09 \pm 0.02$ & $0.11 \pm 0.01$ & 0.150 \\
\hline$\sum \mathrm{SFA}$ & $23.30 \pm 1.43$ & $26.08 \pm 1.59$ & 0.019 \\
\hline Myristoleic acid (C 14:1) & $0.05^{\mathrm{b}} \pm 0.01$ & $0.08^{\mathrm{a}} \pm 0.02$ & 0.044 \\
\hline Palmitoleic acid isomer (C 16:1) & $0.34^{\mathrm{b}} \pm 0.03$ & $0.43^{\mathrm{a}} \pm 0.07$ & 0.028 \\
\hline Palmitoleic acid (C 16:1n7) & $2.59 \pm 0.62$ & $3.55 \pm 0.44$ & 0.073 \\
\hline Octadecenoic acid isomer A (C 18:1) & $0.26 \pm 0.06$ & $0.29 \pm 0.01$ & 0.557 \\
\hline Octadecenoic acid isomer B (C18:1) & $1.39 \pm 0.18$ & $1.80 \pm 0.37$ & 0.060 \\
\hline Elaidic acid (C18:1n9t) & $0.15 \pm 0.02$ & $0.15 \pm 0.03$ & 0.967 \\
\hline Oleic acid $(\mathrm{C} 18: 1 \mathrm{n} 9 \mathrm{c})$ & $29.47 \pm 2.10$ & $30.64 \pm 1.50$ & 0.340 \\
\hline Eicosenoic acid (C20:1n9) & $0.27^{Y} \pm 0.02$ & $0.36^{\mathrm{x}} \pm 0.03$ & $<0.001$ \\
\hline$\sum$ MUFA & $34.52 \pm 0.02$ & $37.30 \pm 2.43$ & 0.127 \\
\hline Octadecadienoic acid isomer A (C 18:2) & $0.11 \pm 0.02$ & $0.12 \pm 0.04$ & 0.446 \\
\hline Octadecadienoic acid isomer B (C 18:2) & $0.06 \pm 0.01$ & $0.08 \pm 0.03$ & 0.191 \\
\hline Octadecadienoic acid isomer C (C 18:2) & $0.07 \pm 0.01$ & $0.07 \pm 0.02$ & 0.762 \\
\hline Octadecadienoic acid isomer D (C 18:2) & $0.75 \pm 0.24$ & $0.87 \pm 0.17$ & 0.392 \\
\hline Linoleic (C 18:2n6) & $34.80^{\mathrm{a}} \pm 2.79$ & $29.10^{b} \pm 3.66$ & 0.024 \\
\hline$\gamma$-linolenic (C 18:3n6) & $0.20 \pm 0.03$ & $0.20 \pm 0.04$ & 0.811 \\
\hline Eicosadienoic (C 20:2n6) & $0.44 \pm 0.09$ & $0.37 \pm 0.09$ & 0.213 \\
\hline Eicosatrienoic acid (C:20:3n6) & $0.40^{\mathrm{b}} \pm 0.04$ & $0.48^{\mathrm{a}} \pm 0.05$ & 0.022 \\
\hline Arachidonic acid (C 20:4n6) & $2.83 \pm 0.86$ & $3.48 \pm 0.64$ & 0.216 \\
\hline Docosatetraenoic acid (C2 2:4n6) & $0.23 \pm 0.13$ & $0.28 \pm 0.07$ & 0.503 \\
\hline$\sum \mathrm{n}-6$ PUFA & $39.89 \pm 3.88$ & $35.05 \pm 3.74$ & 0.079 \\
\hline$\alpha$-linolenic acid (C 18:3n3) & $1.57^{x} \pm 0.10$ & $0.87^{Y} \pm 0.11$ & $<0.001$ \\
\hline Eicosatrienoic (C 20:3n3) & $0.03^{\mathrm{A}} \pm 0.01$ & $0.01^{\mathrm{B}} \pm 0.01$ & 0.003 \\
\hline Eicosapentaenoic acid (C 20:5n3) & $0.13 \pm 0.02$ & $0.15 \pm 0.02$ & 0.175 \\
\hline Docosapentaenoic acid (C22:5n3) & $0.33 \pm 0.10$ & $0.30 \pm 0.06$ & 0.578 \\
\hline Docosahexaenoic acid (C22:6n3) & $0.24 \pm 0.10$ & $0.23 \pm 0.04$ & 0.928 \\
\hline$\sum \mathrm{n}-3$ PUFA & $2.29^{\mathrm{x}} \pm 0.25$ & $1.57^{\mathrm{Y}} \pm 0.15$ & $<0.001$ \\
\hline n-6/n-3 PUFA & $17.43^{Y} \pm 0.72$ & $22.36^{\mathrm{X}} \pm 0.79$ & $<0.001$ \\
\hline
\end{tabular}

SO 3\% sunflower oil, MTO 3\% milk thistle oil; $\bar{x}=$ arithmetic means; $\mathrm{SD}=$ standard deviation; ${ }^{\mathrm{a}, \mathrm{b}} P<0.05$; ${ }^{\mathrm{A}, \mathrm{B}} P<0.01 ;{ }^{\mathrm{X}, \mathrm{Y}} \mathrm{P}<0.001$ 
Table 5. Influence of Silybum marianum oil feed supplementation on antioxidative status of chicken liver $(\mathrm{n}=27)$.

\begin{tabular}{lccr}
\hline Indicator & SO group $\bar{x} \pm \mathrm{SD}$ & MTO group $\bar{x} \pm \mathrm{SD}$ & $P$ value \\
\hline Free sulfhydryl groups $\left(\mu \mathrm{mol} / \mathrm{g}_{\text {liver }}\right)$ & $0.71 \pm 0.09$ & $0.73 \pm 0.14$ & 0.558 \\
Catalase activity $(\mathrm{U} / \mathrm{mg})$ & $67.62^{\mathrm{b}} \pm 33.07$ & $83.09^{\mathrm{a}} \pm 9.21$ & 0.020 \\
Glutathione-S-transferase activity $(\mathrm{mU} / \mathrm{mg})$ & $118.10^{\mathrm{A}} \pm 13.48$ & $101.55^{\mathrm{B}} \pm 18.83$ & 0.005 \\
Glutathione-reductase activity $(\mathrm{mU} / \mathrm{mg})$ & $13.22^{\mathrm{x}} \pm 3.65$ & $9.36^{\mathrm{Y}} \pm 2.03$ & $<0.001$ \\
\hline
\end{tabular}

SO 3\% sunflower oil, MTO 3\% milk thistle oil; $\bar{x}=$ arithmetic means; $\mathrm{SD}=$ standard deviation; ${ }^{\mathrm{a}, \mathrm{b}} P<0.05$; ${ }^{\mathrm{A}, \mathrm{B}} \mathrm{P}<0.01 ;{ }^{\mathrm{X}, \mathrm{Y}} \mathrm{P}<0.001$

$\mathrm{pH}_{\mathrm{u}} 24 \mathrm{~h}$ post-slaughter was 6.1 in domestic broilers, and 5.79 in Arbor Acres broilers. Kralik et al. (2014a) reported $\mathrm{pH}$ values in breast muscles of Cobb 500 broilers as follows: $\mathrm{pH}_{\mathrm{i}}$ 5.95-6.2, and $\mathrm{pH}_{\mathrm{u}}$ 5.73-5.84, which is in line with the results of the present research.

Broiler meat colour depends on the genotype (Fletcher 1995), age (Fanatico et al. 2005), animal technology conditions, and feeding regime (Ponte et al. 2008). Hus ak et al. (2008) stated that the colour of breast muscles of Arbor Acres broilers was: CIE L* value 62.57, CIE a* value 11.87, and CIE b* value 11.37. Lonergan et al. (2003) reported the following breast colour values in 8-week-old broilers: CIE L* 40.31; CIE a* 6.08 and CIE $b^{*}$ 12.52. Fraqueza et al. (2006) classified breast meat as PSE if CIE L* value $>50$, and $\mathrm{pH}_{\mathrm{u}}$ value $<5.8$. According to Petracci et al. (2004), the colour of breast meat (CIE L* value) should be 41-68, Lesiow et al. (2007) set that value range at 43-56, and Woelfel et al. (2002) at 42-71. Fletcher (1999) studied the correlation between breast muscle colour and $\mathrm{pH}_{2}$ values. On the basis of obtained indicators, muscle tissue was classified to lighter than normal (CIE L* $>48.8$ and $\mathrm{pH}_{2}$ 5.63), normal $(48.8 \geq \mathrm{CIE} \mathrm{L*} \leq 43.1$, mean values were 45.6 and $\mathrm{pH}_{2}$ 5.70), and darker than normal ( $\mathrm{L}^{*}<43.1$ and $\mathrm{pH}_{2} 5.81$ ). Accordingly, there is a clear correlation between $\mathrm{CIE} \mathrm{L}^{*}$ values and $\mathrm{pH}_{2}$ values in broiler breast muscles. The colour of muscle tissue is important for the consumers' perception; therefore, produced meat should have optimal values for colour. Van Laack et al. (2000) classified breast muscle tissue as lighter than normal (CIE L* $>60.0$ ) and normal (CIE L* $\leq$ 55.0). Kralik et al. (2014a) investigated the breast muscle colour of Cobb 500 broilers and determined the variability for the following indicators: CIE L* 53.34-55.29, CIE a* 1.782.88 and CIE $b^{*}$ 7.34-8.32. Kralik et al. (2014b) also investigated the indicators of breast meat quality with respect to meat colour. On the basis of paleness (CIE L*), breast meat was classified as DFD (CIE L* < 44), "normal" (CIE L* = 44-53) and PSE (CIE L*> 53). Seventy five percent of breast meat from Cobb 500 and $70 \%$ from Hubbard Classic were classified as "normal". Breast meat classified as PSE had higher CIE L*, lower $\mathrm{pH}_{\text {und }}$ and higher drip loss $(\%)$ than meat of normal characteristics. The opposite was found for DFD meat. Negative correlation between CIE $\mathrm{L}^{*}$ and $\mathrm{pH}_{u}$ and positive correlations between CIE L* and CIE $b^{*}$ values, as well as between CIE L* and drip loss (\%) in both hybrid lines were determined. Abdullah et al. (2010) investigated meat quality indicators of commercial broiler hybrids and determined that cooking loss was between $28.45-28.95 \%$, W.H.C. $15.10-19.12 \%$, and shear force $1.49-2.74 \mathrm{~kg} / \mathrm{cm}^{2}$. Kralik et al. (2014a) reported that drip loss value in breast muscles of 42-day-old Cobb 500 broilers varied from 3.09$4.14 \%$, cooking loss was $21.49-33.29 \%$, and shear force was $35.38-39.93 \mathrm{~N}$.

According to the antioxidant status of broiler liver, authors of the present paper found significantly higher catalase activity in the MTO group. Silymarin proved to have strong antioxidant and hepatoprotective effects on the liver after induced hepatocellular damage in rats (Pradeep et al. 2007). Recent investigation showed that silymarin functioned as a 
free radical scavenger, increasing reduced available glutathione (GSH) which functions as detoxicant of intermediary oxygen reactive products of lipoperoxidation (S o to et al. 2003). In a situation with increased reactive oxygen species (ROS) production, significant increase in the activities of SOD, GSHPX, and CAT in mice organs such as liver were measured (Sonnenbichler et al. 1976). They reported that transcription in the livers of rats and mice was accelerated in vivo under the influence of silymarin. Therefore, it can be supposed that Silybum marianum oil used in this study led to induced liver catalase biosynthesis, enhancing hepatocellular antioxidant defence. This is not in accordance with Blevins et al. (2010), who reported no influence of silymarin on the glutathione $\mathrm{S}$ transferase activity in broiler liver. Kiruthiga et al. (2007) found that silymarin prevented reduction in GSH activity, which was not the case in our research. The increase in hydrogen peroxide removal by liver catalase, and the subsequent decrease in $\mathrm{H}_{2} \mathrm{O}_{2}$ derived-ROS probably lead to a decrease of other antioxidative liver enzymes activities, such as glutathione-S-transferase, and glutathione reductase.

\section{Acknowledgment}

The research was carried out within the project "Pig and Poultry Growth Characteristics and Quality of Products" (No. 079-0790566-0567), funded by the Ministry of Science, Education and Sports of the Republic of Croatia.

\section{References}

Abdullah AY, Al-Beitawi NA, Rjoup MMS, Qudsieh RI, Ishmais MAA 2010: Growth performance, carcass and meat quality characteristics of different commercial crosses of broiler strains of chicken. J Poult Sci 47: 13-21

Aebi HE 1986: Catalase. In: Methods of enzymatic analysis. $3^{\text {rd }}$ edn, Bergemeyer HU (Ed.), VCH Verlagsgesellschaft mbH, Weinheim, pp 273-286

Blevins S, Siegel PB, Blodgett DJ, Ehrich M, Saunders GK, Lewis RM 2010: Effects of silymarin on gossypol toxicosis in divergent lines of chickens. Poultry Sci 89: 1878-1886

Bosisio E, Beneli C, Pirola O 1992: Effect of the flavanolignans of Silybum marianum L. on lipid peroxidation in rat liver microsomes and freshly isolated hepatocytes. Pharmacol Res 25:147-165

Bradford MM 1976: A rapid and sensitive method for the quantification of microgram quantities of protein utilizing the principle of protein-dye binding. Anal Biochem 72: 248-254

Commission Regulation (EC) No 543/2008 laying down detailed rules for the application of Council Regulation (EC) No 1234/2007 as regards the marketing standards for poultry meat.

Cortinas L, Villaverde J, Galobart J, Baucells MD, Codony R, Barroeta AC 2004: Fatty acid content in chicken thigh and breast as affected by dietary polyunsaturation level. Poultry Sci 83: 1155-1164

Csapó J, Sugár L, Horn A, Csapó J 1986: Chemical composition of milk from red deer, roe and fallow deer kept in captivity. Acta Agron Hung 3-4: 359-372

De La Puerta R, Martinez E, Bravo L 1996: Effect of silymarin on different acute inflammation models and leucocyte migration. J Pharm Pharmacol 48: 968-970

Elmakki AM, Abdel Atti AK, Dousa MB, Elagib AAH, Malik EEH, Elamin MK 2013: Effect of treated cowpea seeds on broiler chicken. GJASR 1: 68-68

Fanatico AC, Pillai PB, Cavitt LC, Owens CM, Emmert JL 2005: Evaluation of slower-growing broiler genotypes grown with and without outdoor access: growth performance and carcass yield. Poultry Sci 84: 1321-1327

Fiebrich F, Koch H 1979: Silymarin, an inhibitor of lipoxygenase. Experientia 35: 1548-1560

Fletcher DL 1995: Relationship of breast meat color variation to muscle pH and texture. Poultry Sci 74: 120 (Abstr.)

Fletcher DL 1999: Broiler breast meat color variation, pH, and texture. Poultry Sci 78: 1323-1327

Fraqueza MJ, Cardoso AS, Ferriera MC, Barreto AS 2006: Incidence of pectoralis major turkey muscles with light and dark color in a Portuguese slaughterhouse. Poultry Sci 85: 1992-2000

Habdous M, Vincent-Viry M, Visvikis S, Siest G 2002: Rapid spectrophotometric method for serum glutathione S-transferase activity. Clin Chim Acta 326: 131-142

Habig WH, Pabst MJ, Jakoby WB 1974: Glutathione S-transferases. The first enzymatic step in mercapturic acid formation. Journal Biol Chem 249: 7130-7139

Honikel KO 1998: Reference methods for the assessment of physical characteristics of meat. Meat Sci 49: 447-457

Husak R, Sebranek J, Bregendahl K 2008: A survey of commercially available broilers marketed as organic, free-range, and conventional broilers for cooked meat yields, meat composition, and relative value. Poultry Sci 87: 2367-2376 
Kang JS, Jeon YJ, Park SK, Yang KH, Kim HM 2004: Protection against lipopolysaccharide-induced sepsis and inhibition of interleukin-1 $\beta$ and prostaglansin E2 syntesis by silymarin. Biochem Pharmacol 87: 175-181

Kiruthiga PV, Shafreen RB, Pandian SK, Arun S, Govindu S, Devi KP (2007): Protective effect of silymarin on erythrocyte haemolysate against benzopyrene and exogenous reactive oxygen species $\left(\mathrm{H}_{2} \mathrm{O}_{2}\right)$ induced oxidative stress. Chemosphere 68: 1511-1518

Kralik G, Kralik Z, Grčević M, Škrtić Z 2012: Enrichment of poultry products with functional ingredients. Poljoprivreda/Agriculture 18: 52-59

Kralik G, Sak-Bosnar M, Kralik Z, Galović O 2014a: Effect of $\beta$-alanine dietary supplementatiton on concentration of carnosine and quality of broiler muscle tissue. J Poult Sci 51: 151-156

Kralik G, Djurkin I, Kralik Z, Škrtić Z, Radišić Ž 2014b: Quality indicators of broiler breast meat in relation to colour. Anim Sci Pap Rep 32: 173-178

Kralik Z, Kralik G, Radišić Ž, Kralik I, Hanžek D 2015: Influence of dietary replacement of sunflower oil with milk thistle (Silybum marianum) oil on fattening characteristics and carcass quality of broilers. XI. Kábrtovy Dietetické Dny (Eds: Strakova E, Suchy P, ISBN 978-80-263-0901-7), 14 May 2015, Brno, Czech Republic, pp. $74-83$

Le Bihan-Duval E, Debut M, Berri CM, Sellier N, Sante-Lhoutellier V, Jego Y, Beaumont C 2008: Chicken meat quality: genetic variability and relationship with growth and muscle characteristics. BMC Genetics 9: 53

Lesiow T, Oziemblowski M, Szkudlarek S 2007: Incidence of PSE and DFD in chicken broiler breast muscles 24 h. p.m. Proceedings of XVII European Symposium on the Quality of Poultry Meat and XII European Symposium on the Quality of Eggs and Egg Products. Prague, Czech Republic, pp 265-266

Liu Y, Lyon BG, Windham WR, Lyon CE, Savage EM. 2004: Principal component analysis of physical, color, and sensory characteristics of chicken breasts deboned at two, four, six, and twenty-four hours post-mortem. Poultry Sci 83: 101-108

Lonergan SM, Deeb N, Fedler CA, Lamont SJ 2003: Breast meat quality and composition in unique chicken populations. Poultry Sci 82: 1990-1994

Luper S 1998: A review of plants used in the treatment of liver disease: Part 1. Alternat Med Rev 3: 410-421

Mekala P, Punniamurthy N, Hariharan P 2006: Protective effect of curcumin and silymarin against aflatoxicosis in broiler chicken. Indian Vet J 83: 501-503

Mojahedtalab AR, Mohammadi M, Roostaei-Ali Mehr M, Asadi M 2013: Effect of silymarin on performance and immune responses of broilers. Anim Prod Res 2: 49-58

Petracci M, Bianchi M, Betti M, Cavani C 2004: Color variation and characterisation of broiler breast meat during processing in Italy. Poultry Sci 83: 2086-2092

Polyak SJ, Morishima C, Shuharti MC, Wang CC, Liu Y, Lee DYW 2007: Inhibition of T-cell inflammatory cytokines, hepatocyte NF-kB signalling and HCV infection by standardized silymarin. Gastroenterology 132: 1925-1936

Ponte PIP, Rosado CMC, Crespo JP, Crespo DG, Mourao MA, Chaveiro-Soares MA, Bras JLA, Mendes I, Gama LT, Prates AM, Ferreira LMA, Fontes CMGA 2008: Pasture intake improves the performance and meat sensory attribute of free-range broilers. Poultry Sci 87: 71-79

Pradeep K, Mohan CVR, Gobianand K, Karthikeyan S 2007: Silymarin modulates the oxidant-antioxidant imbalance during diethylnitrosamine induced oxidative stress in rats. Eur J Pharmacol 560: 110-116

Raach-Moujahed A, Haddad B 2013: Performance, livability, carcass yield and meat quality of Tunisian local poultry and fast-growing genotype (Arbor Acres) fed standard diet and raised outdoor access. J Anim Prod Adv 3: 75-85

Sedlak J, Lindsay RH 1968: Estimation of total, protein-bound, and nonprotein sulfhydryl groups in tissue with Ellman's reagent. Anal Biochem 25: 192-205

Scott L 1998: A review of plant used in the treatment of liver disease: Part 1. Alternat Med Rev 3: 410-426

Schiavone A, Righi F, Quarantelli A, Bruni R, Serventi P, Fusari A 2007: Use of Silybum marianum fruit extract in broiler chicken nutrition: influence on performance and meat quality. J Animal Physiol Anim Nutr 91: 256-262

Sonnenbichler J, Goldberg M, Hane L 1976: Stimulatory effect of silibinin on the DNA synthesis in partially hepatectomized rat livers; non-response in hepatoma and other malignant cell lines. Biochem Pharmacol 35: 538-541

Soto C, Recoba R, Berron H, Alvarez C, Favari L 2003: Silymarin increases antioxidant enzymes in alloxaninduced diabetes in rat pancreas. Comp Biochem Phys C 136: 205-212

Yakhkeshi S, Rahimi S, Hemati Matun HR 2012: Effects of yarrow (Achillea millefolium L.), antibiotic and probiotic on performance, immune response, serum lipids and microbial population of broilers. J Agr Sci Techn 14: 799-810

Youdim KA, Martin A, Joseph JA 2000: Essentials fatty acids and the brain; possible health implications. Int J Dev Neurosci 18: 383-399

Van Laack RLJM, Liu CH, Smith MO, Loveday HD 2000: Characteristics of pale, soft, exudative broiler breast meat. Poultry Sci 79: 1057-1061

Woelfel RL, Owens CM, Hirschler EM, Martinez-Dawson R, Sams AR 2002: The characterisation and incidence of pale, soft, and exudative broiler meat in a commercial processing plant. Poultry Sci 81: 579-584 